\title{
Acute Liver Dysfunction in the Course of Norovirus Gastroenteritis
}

\author{
H. Nakajima T. Watanabe T. Miyazaki M. Takeuchi \\ Y. Honda N. Shimada K. Nakanishi Y. Urita \\ M. Sugimoto \\ Department of General Medicine and Emergency Care, Toho University, Tokyo, \\ Japan
}

\section{Key Words}

Acute gastroenteritis · Liver dysfunction · Norovirus

\begin{abstract}
A 48-year-old female with abdominal pain and malaise who showed delayed symptom of acute gastroenteritis came to see us. Her illness was diagnosed as norovirus infection, but liver dysfunction accompanied this gastroenteritis. We investigated the pathogenesis of this hepatitis for all causes including drugs, but we could not detect norovirus infection. The liver damage improved shortly in course of the gastroenteritis. She recovered completely within 2 weeks without any damage left. Norovirus-induced liver dysfunction is not known, and there is no report in the literature. We report, for the first time, the case of liver dysfunction with norovirus gastroenteritis.
\end{abstract}

\section{Introduction}

Before 1993, the former viruses of present norovirus were diagnosed by means of electron microscopy using stool samples. They were called in the literature, according to their shape, 'small round structured virus' (SRSV), or due to their similarity to the Norwalk agent (Norwalk-like viruses) were named after the location where they were found. After sequencing was accomplished, the broad sense of Norwalk-like virus genome revealed a single positive-strand RNA enclosed in a non-enveloped protein coat with distinct cup-shaped depression that placed it as a new genus 'norovirus' in the family Caliciviridae, whose name is derived from calyx, meaning cup in Greek [1].

Norovirus is now recognized as being the leading cause of epidemics of gastroenteritis and an important cause of sporadic gastroenteritis in both children 
and adults. A recent review of studies documented norovirus in 5-31\% of patients hospitalized for gastroenteritis and in $5-36 \%$ of those visiting a clinic, making it the most common cause in children [2]. We report the case of a healthy female with acute norovirus gastroenteritis who developed acute liver damage during the infectious gastroenteritis.

\section{Case Report}

A 48-year-old female visited with abdominal pain and malaise. She also complained of loose stool following them and nausea, but no vomiting. She described the pain as intermittent dull pain in the whole abdomen without any exacerbating or relieving factors, which radiated to the back, shoulder, and neck. She had a medical past history of cholelithiasis and had undergone cholecystectomy 4 years before. There was no problem after surgical treatment and her liver function was normal. She drank a can of beer every day, but liver damage had not been pointed out. She had eaten raw fish 5 days before onset of this illness, but she denied any ingestion of oyster, raw shellfish, raw pork, or venison. She had no usual medication and no antecedent travel history. She felt acute moderate distress of the whole abdomen, but physical examination showed soft abdomen, tenderness especially in epigastrium and right hypochondrium; Murphy's sign phenomenon was unclear. We did not find jaundice, hepatosplenomegaly, or knock pain on the back. Abdominal ultrasonography was carried out. No dilation of the common bile duct or bile duct stone was found; the intrahepatic bile duct and the pancreatic duct were normal. Abdominal CT revealed no abnormality. We could thus exclude an episode referring to her past history. However, laboratory values on admission (table 1) showed moderate elevation of aspartate aminotransferase (AST) up to $651 \mathrm{IU} / \mathrm{l}$, alanine aminotransferase (ALT) up to $146 \mathrm{IU} / \mathrm{l}$, lactate dehydrogenase (LDH) up to $457 \mathrm{IU} / \mathrm{l}$, but there was no elevation of total bilirubin (T-Bil), direct bilirubin (D-Bil) or alkaline phosphatase (ALP). HBs antigen (HBsAg) and HCV antibody (HCVAb) were both negative. Other hepatitis viruses such as HAV and HEV were all negative, and other viruses which can cause liver dysfunction were not detected. We confirmed that Epstein-Barr virus, cytomegalovirus and human herpesvirus were negative. On the second hospital day, AST rose up to $892 \mathrm{IU} / \mathrm{l}$ and ALT up to $445 \mathrm{IU} / \mathrm{l}$. The same day, watery diarrhea more than 10 times daily occurred. On the third hospital day, the laboratory values peaked out, and on the fourth day, the symptoms improved (fig. 1). Stool culture for pathogenic bacteria turned out to be negative, and norovirus was detected by viral antigen check and confirmed by reverse transcription polymerase chain reaction. Its genogroup and genotype analysis showed that the strain was GII 4. Other enteric pathogenic viruses such as rotavirus, adenovirus, astrovirus, norovirus or sapovirus were not detected. The only pathogen related to her illness was norovirus.

The patient recovered satisfactorily by supportive therapy and was discharged on the 7th hospital day, with improvement of liver dysfunction as AST $98 \mathrm{IU} / \mathrm{l}$ and ALT $30 \mathrm{IU} / \mathrm{l}$. Her liver damage was normalized completely on the 14th day as AST $32 \mathrm{IU} / \mathrm{l}$ and ALT $30 \mathrm{IU} / \mathrm{l}$.

\section{Discussion}

Human norovirus has been most recently established compared to other enteric viruses such as rotavirus, adenovirus and astrovirus. Its infectious potential is estimated to be very high among these viruses; it is one of the most prevalent enteric viruses causing acute gastroenteritis in children of all ages. The virus is sometimes thought to lead to whole body infection. There was a report that murine norovirus infection of mice is associated with initial enteric seeding and subsequent extraintestinal spread [1], and other reports followed [2]. While it has long been believed that norovirus infection is confined to the intestine, there is no direct proof for this claim, and several recent findings [3] suggest that this theory be re-considered. A recent study found norovirus RNA in the serum of $15 \%$ of infected individuals [4]. A work in animal models of norovirus infection supports virus dissemination past the 
intestine, too [5]. Murine norovirus 1 (MNV-1) replicates efficiently in the spleen and induces specific splenic histological changes, including activation of cells in the white pulp and hypertrophy of cells in the red pulp [6]. As norovirus diagnostics have improved, there have been numerous reports of norovirus associations with clinical outcomes other than gastroenteritis. For example, one case report detected norovirus RNA in the serum and cerebrospinal fluid of a child with encephalopathy [3]. In addition, central nervous system damages during a norovirus outbreak among military personnel in Afghanistan were reported [7].

The possibility that human noroviruses disseminate to peripheral sites is a clinically relevant question, since mild or sporadic pathologies associated with human norovirus infection of peripheral tissues may have been missed due to difficulties in their detection and the assumption that they are limited to the intestinal tract. There have been several recent associations between norovirus infection and extraintestinal involvement showing disseminated intravascular coagulation [8] and infantile convulsion $[9,10]$.

However, there is no report of liver damage [2] caused by norovirus infection, only of rotavirus hepatitis in a child [8]. Referring to viral hepatitis, the concurrent presence of norovirus and hepatitis A virus was pointed out and potential risk of hepatitis was worried about $[6,11]$. As we could exclude all other causes for liver damage, we report the case of a normal adult female with acute norovirus gastroenteritis who developed acute liver damage during infection. We experienced liver dysfunction in the course of rotavirus infection except for this case. We also speculate that there may be low-grade damage of liver function in norovirus gastroenteritis, but we might not catch occasionally the minimal changes before they disappear after a short period. To evaluate the liver dysfunction forward to further argument [12], we should pay attention not only to intestinal symptoms, but also to liver function in viral gastroenteritis.

While this case report provides only anecdotal evidence that norovirus infection can have varied clinical outcomes, it adds proof suggesting that enteric viruses should be considered as potential etiological agents of diseases other than gastroenteritis [13]. 
Table 1. Laboratory data on admission

\begin{tabular}{llllll}
\hline CBC and coagulation & \multicolumn{3}{c}{ Chemistry } & \multicolumn{2}{l}{ Virus marker } \\
WBC & $10,200 / \mathrm{mm}^{3}$ & Amy & $49 \mathrm{IU} / \mathrm{l}$ & HBsAg & - \\
RBC & $409 \times 10^{4} / \mu \mathrm{l}$ & Amy-P & $27 \mathrm{IU} / \mathrm{l}$ & HCVAb & - \\
$\mathrm{HGB}$ & $9.0 \mathrm{~g} / \mathrm{dl}$ & $\mathrm{CK}$ & $42 \mathrm{IU} / \mathrm{l}$ & & \\
$\mathrm{HCT}$ & $30.0 \%$ & $\mathrm{CK}-\mathrm{MB}$ & $7 \mathrm{IU} / \mathrm{l}$ & Urinalysis & \\
MVC & $73 \%$ & $\mathrm{BUN}$ & $1.5 \mathrm{mg} / \mathrm{dl}$ & $\mathrm{pH}$ & 7.0 \\
PLT & $22.1 \times 10^{4} / \mu \mathrm{l}$ & $\mathrm{Cr}$ & $0.6 \mathrm{mg} / \mathrm{dl}$ & SP gravity & 1.020 \\
PT & $>100 \%$ & $\mathrm{UA}$ & $4.3 \mathrm{mg} / \mathrm{dl}$ & Prot & \pm \\
& & $\mathrm{Na}$ & $138 \mathrm{mEq} / \mathrm{l}$ & Glu & - \\
Chemistry & & $\mathrm{K}$ & $4.3 \mathrm{mEq} / \mathrm{l}$ & Blood & \pm \\
TP & $6.5 \mathrm{~g} / \mathrm{dl}$ & $\mathrm{Cl}$ & $105 \mathrm{mEq} / \mathrm{l}$ & Ketone & \pm \\
Alb & $4.1 \mathrm{~g} / \mathrm{dl}$ & $\mathrm{Glu}$ & $130 \mathrm{mg} / \mathrm{dl}$ & Urobil & \pm \\
T-Bil & $1.0 \mathrm{mg} / \mathrm{dl}$ & $\mathrm{CRP}$ & $0.2 \mathrm{mg} / \mathrm{dl}$ & Bil & - \\
D-Bil & $0.3 \mathrm{mg} / \mathrm{dl}$ & & & Nitr & - \\
AST & $651 \mathrm{IU} / \mathrm{l}$ & & & WBC & - \\
ALT & $146 \mathrm{IU} / \mathrm{l}$ & & & & \\
LDH & $457 \mathrm{IU} / \mathrm{l}$ & & & & \\
ALP & $314 \mathrm{IU} / \mathrm{l}$ & & & &
\end{tabular}

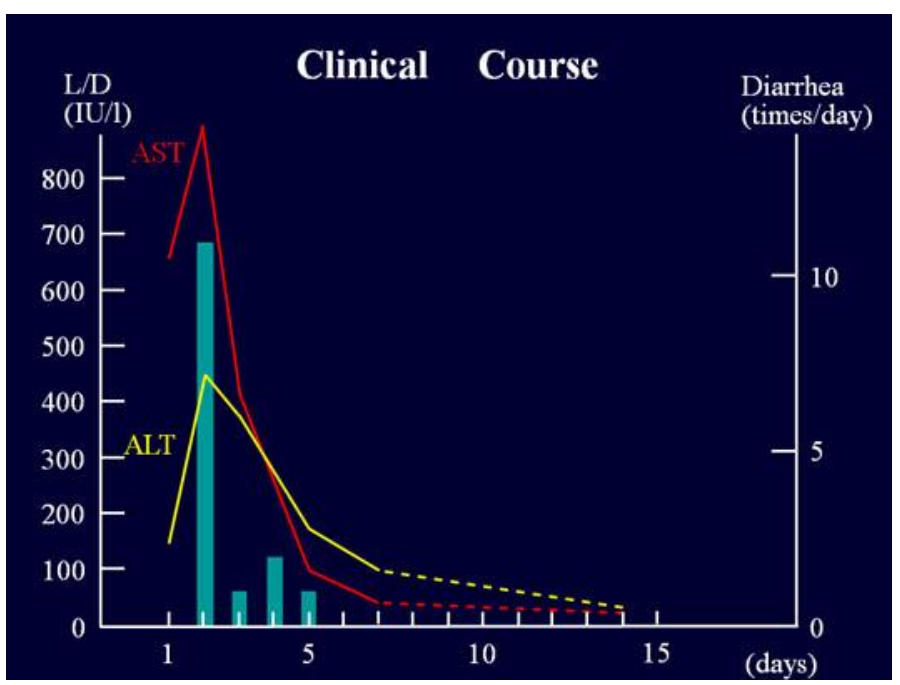

Fig. 1. Clinical course of the case. This schema shows the course of liver dysfunction which happened promptly and receded soon together with the improvement of acute gastroenteritis. 


\section{References}

1 Souza M, Azevedo MSP, Jung K, et al: Pathogenesis and immune responses in gnotobiotic calves after infection with the genogroup II.4-HS66 strain of human norovirus. J Virol 2008;82:1777-1786.

-2 Takanashi S, Hashira S, Matsunaga T, et al: Detection, genetic characterization, and quantification of norovirus RNA from sera of children with gastroenteritis. J Clin Virol 2009;44:161-163.

-3 Mumphrey SM, Changotra H, Moore TN, et al: Murine norovirus 1 infection is associated with histopathological changes in immunocompetent hosts, but clinical disease is prevented by STAT1-dependent infection responses. J Virol 2007;81:3251-3263.

-4 Patel MM, Widdowson MA, Glass RI, et al: Systematic literature review of role of noroviruses in sporadic gastroenteritis. Emerg Infect Dis 2008;14:1224-1231.

5 Cheetham S, Souza M, Meulia T, et al: Pathogenesis of a genogroup II human norovirus in gnotobiotic pigs. J Virol 2006;80:10372-10381.

-6 Mesquita JR, Vaz L, Cerqueira S, et al: Norovirus, hepatitis A virus and enterovirus presence in shellfish from high quality harvesting areas in Portugal. Food Mibrobiol 2011;28:936-941.

7 Ito S, Takeshita S, Nezu A: Norovirus associated encephalopathy. Pediatr Infect Dis J 2006;25:651-652.

8 Centers for Disease Control and Prevention: Outbreak of acute gastroenteritis associated with Norwalklike viruses among British military personnel - Afghanistan, May 2002. MMRW Morb Mortal Wkly Rep 2002;51:477-479.

$>9$ Kawano G, Oshige KI, Syutou S, et al: Benign infantile convulsions associated with mild gastroenteritis: A retrospective study of 39 cases including virological tests and efficacy of anticonvulsants. Brain Dev 2007;29:617-622.

10 Chen S, Tsai C, Lai M, et al: Norovirus infection as a cause of diarrhea-associated benign infantile seizures. Clin Infect Dis 2009;48:849-855.

11 Morales-Rayas R, Wolffs OFG, Griffiths MW: Simultaneous separation and detection of hepatitis A and norovirus in produce. Int J Food Microbiol 2010;139:48-55.

12 Karst AM: Pathogenesis of noroviruses, emerging RNA viruses. Viruses 2010;2:748-781.

$\checkmark 13$ Venuta A, Bertolani P, Mazzali E, et al: Acute hepatitis in course of rotavirus gastroenteritis: a case report. Pediatr Med Chir 2005;27: 41-42. 